\title{
Eucalyptus leaf extract inhibits intestinal fructose absorption, and suppresses adiposity due to dietary sucrose in rats
}

\author{
Keiichiro Sugimoto ${ }^{1,2}$, Junko Suzuki ${ }^{3}$, Kazuya Nakagawa $^{2}$, Shuichi Hayashi ${ }^{2}$, Toshiki Enomoto ${ }^{4}$, \\ Tomoyuki Fujita $^{3}$, Ryoichi Yamaji ${ }^{1,3}$, Hiroshi Inui ${ }^{1,3 *}$ and Yoshihisa Nakano ${ }^{1,3}$ \\ ${ }^{1}$ Center for Research and Development of Bioresources, Osaka Prefecture University, Sakai, Osaka 599-8531, Japan \\ ${ }^{2}$ Research and Development Center, Nagaoka Perfumery Co. Ltd, Ibaraki, Osaka 567-005, Japan \\ ${ }^{3}$ Department of Applied Biological Chemistry, Osaka Prefecture University, Sakai, Osaka 599-8531, Japan \\ ${ }^{4}$ Department of Food Science, Ishikawa Agricultural College, Nonoichi, Ishikawa 921-8836, Japan
}

(Received 24 June 2004 - Revised 18 January 2005 - Accepted 23 January 2005)

\begin{abstract}
Sucrose is more lipogenic than starch, and the extreme ingestion of sucrose induces adiposity and obesity. The aim of this study was to examine the effect of the eucalyptus (Eucalyptus globulus) leaf extract (ELE) on adiposity due to dietary sucrose in rats. In addition, in this study, the effect of ELE on intestinal fructose absorption was also examined. Rats were fed a high-sucrose diet (75\% in calorie base) with or without ELE (10 g/kg diet) for 5 weeks. Body weight was lower in the rats receiving ELE than in the controls (342 (SD 37.9) v. 392 (SD 26.0) g $(n$ 7); $P<0.05$ ). Furthermore, ELE resulted in decreases in the triacylglycerol concentrations in the plasma (1.44 (SD 0.448) v. 2.79 (SD 0.677) mmol/l $(n$ 7); $P<0.05$ ) and liver (19.1 (SD 5.07) v. 44.1 (SD 16.28) $\mu \mathrm{mol} / \mathrm{g}(n$ 7); $P<0.05$ ). In contrast, ELE did not show any significant effects in the rats fed a starch diet. When rats were orally given ELE 10 min before fructose administration, the intestinal fructose absorption, which was examined by measuring the elevated concentration of fructose in the portal vein at 30 min after the fructose administration, was significantly inhibited in a dose-dependent manner. Furthermore, in rats fed a high-fructose diet, the plasma and hepatic triacylglycerol concentrations were significantly decreased by ELE. These results indicate that ELE, which inhibits the intestinal fructose absorption, can suppress adiposity in rats that ingest large amounts of sucrose or fructose.
\end{abstract}

Adiposity: Dietary sucrose: Intestinal fructose absorption: Eucalyptus: Eucalyptus globulus

Although the major part of dietary carbohydrate is starch, a large amount of sucrose is used in many foods as a sweetener or other ingredients. In addition, high-fructose corn syrups, which are commercially produced by the enzymatic isomerization of glucose, are utilized as a sweetener in soft drinks and other beverages. After the introduction of high-fructose corn syrups, the consumption of free fructose has exponentially increased (Hallfrish, 1990).

Fructose is more lipogenic than glucose, and the plasma and hepatic triacylglycerol (TG) concentrations are significantly elevated by the extreme ingestion of sucrose or fructose (Fukuda et al. 1983). The increased consumption of a fructose-containing diet might be one of the environmental factors contributing to the development of obesity and the accompanying abnormalities of insulin resistance syndrome (Elliott et al. 2002). In addition, dietary fructose results in the elevation of blood pressure, uric acid and lactic acid (Hallfrish, 1990).

Lipogenesis and obesity induced by dietary sucrose could be prevented by inhibiting the sucrase reaction in the small intestine. Indeed, Osaki et al. (2001) have reported that the elevation of the plasma and hepatic concentrations of TG is suppressed in rats fed a sucrose-rich diet when L-arabinose, a sucrase inhibitor, is used as a dietary supplement. However, sucrase inhibitors are ineffective when high-fructose corn syrups, instead of sucrose, are consumed as a sweetener. Fructose is transported across the intestinal brush-border membranes by the specific transporter, GLUT5, in contrast to glucose, which is absorbed from the lumen of the small intestine by the action of the $\mathrm{Na}^{+}$/glucose co-transporter 1 (SGLT1) (Gould \& Holman, 1993; Mahraoui et al. 1994). Thus, if it is possible to inhibit the intestinal fructose absorption specifically, adiposity would be prevented even in subjects who consume not only large amounts of sucrose but also high-fructose corn syrups as a sweetener. However, such inhibitors specific for the intestinal fructose absorption have not yet been found.

Eucalyptus (Eucalyptus globulus) contains a variety of phloroglucinols and hydrolysable tannins. Some of these compounds possess interesting biological activities, such as antioxidation (Amakura et al. 2002), antibacterial (Hou et al. 2000) and antiviral (Takasaki et al. 1990) effects. In Japan, the 'eucalyptus leaf extract' is included as one of the natural food additives used for antioxidation in the List of Existing Food Additives (Japanese Ministry of Health and Welfare, 1999). In addition, this plant, although indigenous to Tasmania, is traditionally used to treat diabetes mellitus in South America and Africa, 
and its antihyperglycaemic effect has been confirmed in streptozotocin-induced diabetic mice (Gray \& Flatt, 1998).

The objective of the present study was to examine the effect of the eucalyptus leaf extract (ELE) on adiposity due to dietary sucrose in rats. In addition, in this study, the effect of ELE on intestinal fructose absorption was also examined.

\section{Materials and methods}

\section{Preparation of eucalyptus leaf extract}

One kilogram of dried eucalyptus ( $E$. globulus) leaves, which were harvested in Spain and purchased from K. Kobayashi \& Co. (Kobe, Japan), were extracted with $10 \mathrm{~kg}$ boiling ethanol-water $(1: 2, v / v)$ under reflux for $2 \mathrm{~h}$. The obtained extract was filtered, evaporated to dryness in vacuo, and used as ELE throughout the experiments. About $200 \mathrm{~g}$ dried ELE was obtained from $1 \mathrm{~kg}$ dried leaves.

\section{Diets and animal housing}

Male Wistar rats were purchased from Kiwa Laboratory Animals (Wakayama, Japan), and maintained on a starch diet for at least 1 week prior to the study. The starch diet contained the following (1 kg): 170 casein, 700 starch, 30 soya bean oil, 35 mineral mixture (AIN-93G-MX; Clea, Tokyo, Japan), 10 vitamin mixture (AIN-93VX; Clea), 3 methionine, 2 choline chloride and 50 cellulose. In addition to the starch diet, a sucrose or fructose diet, in which the corresponding sugar was included instead of starch, was used as the experimental diet. When ELE was supplemented into these experimental diets, a portion of the cellulose was substituted by ELE. These rats were housed individually at controlled temperature $\left(23 \pm 2^{\circ} \mathrm{C}\right)$, humidity $(60 \pm 10 \%)$ and lighting (9.00-21.00 hours), and had free access to the diet and water throughout the experiment. All experimental procedures involving the laboratory animals were approved by the Animal Care and Use Committee of Osaka Prefecture University.

\section{Design of experiments with sucrose-fed rats (Expts 1 and 2)}

In Expt 1, the effect of ELE on the adiposity was studied in rats fed sucrose as a major energy source. Rats (5 weeks old; 142 (SD 8.6) $\mathrm{g}$ ( $n$ 28)), which had been maintained on the starch diet for 1 week, were randomly divided into four groups (seven rats in each group), and fed the starch or sucrose diet with or without ELE $(10 \mathrm{~g} / \mathrm{kg}$ diet) for 5 weeks. During the feeding, the body weight change and food intake were determined. At the end of the feeding, these rats were starved for $16 \mathrm{~h}$, and then anaesthetized with diethyl ether. Blood was sampled from the tail vein, and the concentrations of glucose and TG in the plasma were determined. In addition, the liver and epidydimal adipose tissue were obtained and weighed, and TG concentration in the liver was measured.

In Expt 2, for further elucidation of the preventive effect of ELE on the adiposity induced by dietary sucrose, rats (5 weeks old; 152 (SD 5) g ( $n$ 25)), divided into five groups (each five rats), were fed the sucrose diet containing varied amounts of ELE $(0,0 \cdot 3,1,3$ or $10 \mathrm{~g} / \mathrm{kg}$ diet). After feeding for 2 weeks, these rats were starved for $16 \mathrm{~h}$, and liver was excized under diethyl ether anaesthesia to determine the TG concentration and ketohexokinase (KHK) and glucose 6-phosphate dehydrogenase (G6PDH) activities.

Determination of glucose and triacylglycerols in plasma and liver

The plasma glucose concentration was measured by a glucose oxidase method using a commercially available kit (Glucose B-Test; Wako, Osaka, Japan). TG in the plasma and liver were extracted with isopropanol and determined by an acetylacetone method using a commercial kit (Triglyceride-Test; Wako) according to the manufacturer's instructions.

\section{Enzyme assays}

The liver was homogenized with a polytron homogenizer in $25 \mathrm{mmol} / \mathrm{l}$ HEPES-KOH buffer, $\mathrm{pH} 7 \cdot 4$, containing $0.15 \mathrm{~mol} / \mathrm{l}$ $\mathrm{KCl}$ at $4^{\circ} \mathrm{C}$. After centrifugation at $10000 \mathrm{~g}$ for $20 \mathrm{~min}$, the obtained supernatant was used as a crude enzyme solution for the assays of KHK and G6PDH. The KHK (Bais et al. 1985) and G6PDH (Glock \& MaLean, 1953) activities were measured as references. The protein concentration was determined according to Bradford (1976) using bovine serum albumin as the standard.

\section{Measurement of the sucrase inhibitory activity of eucalyptus leaf extract in vitro (Expt 3)}

A crude sucrase solution was prepared from the rat small intestine as previously described (Takenoshita et al. 1998). The sucrase reaction was carried out at $37^{\circ} \mathrm{C}$ for $30 \mathrm{~min}$ using a reaction mixture $(1 \mathrm{ml})$ containing $50 \mathrm{mmol} / \mathrm{l}$ potassium phosphate buffer, $\mathrm{pH}$ $6.5,25 \mathrm{mmol} / \mathrm{l}$ sucrose and the crude enzyme solution. To examine the sucrase inhibitory activity of ELE, ELE was included at 1, 3 or $10 \mathrm{mg} / \mathrm{ml}$ in the reaction mixture. $(+)$-Catechin $(1,3$ or $10 \mathrm{mg} / \mathrm{ml})$ or $(-)$-epigallocatechin 3 -O-gallate $(0.05,0.1$ or $0.2 \mathrm{mg} / \mathrm{ml}$ ) was also added to the reaction mixture as a sucrase inhibitor. The sucrase reaction was stopped by heating in a boiling water bath for $2 \mathrm{~min}$, and the amount of glucose formed during the reaction was measured by a hexokinase-G6PDH method using a commercial kit (Roche Diagnostics).

\section{Determination of the inhibitory effect of eucalyptus leaf extract on} intestinal fructose absorption (Expt 4)

Rats (8 weeks old; 307 (SD 15.9) g ( $n$ 25)), which had been maintained on the starch diet, were starved for $16 \mathrm{~h}$, and orally given ELE $(0,0.1,0.3$ or $1 \mathrm{~g} / \mathrm{kg}$ body weight; dissolved in $0.5 \mathrm{ml}$ water). Ten minutes later, these rats were orally administered the solution with or without fructose $(2 \mathrm{~g} / \mathrm{kg}$ body weight; dissolved in $0.5 \mathrm{ml}$ water). Blood (about $50 \mu \mathrm{l}$ ) was sampled from the portal vein under diethyl ether anaesthesia at $30 \mathrm{~min}$ after the administration of fructose, and the fructose concentration in the plasma was determined by the fructose dehydrogenase method described by Ameyama et al. (1981) with some modifications. Briefly, plasma sample $(10 \mu \mathrm{l})$ was incubated in a reaction mixture $(1 \mathrm{ml})$ containing $0.1 \mathrm{~mol} / 1$ potassium phosphate buffer, pH $6 \cdot 0,1 \%(\mathrm{v} / \mathrm{v})$ Triton X-100, $0.1 \mathrm{mmol} / \mathrm{l}$ WST-1 (Dojindo, Kumamoto, Japan), 8 mol/l 1-methyl phenazine methosulphate (Dojindo), 5 units $/ \mathrm{ml}$ fructose dehydrogenase (from Gluconobacter sp.; Toyobo, Osaka, Japan), at $30^{\circ} \mathrm{C}$ for $3 \mathrm{~h}$. The concentration of fructose was estimated by measuring the increase in the absorbance at $438 \mathrm{~nm}$ due to the reduction of WST-1 
coupled with the oxidation of fructose during the incubation. To examine the intestinal glucose absorption, rats (8 weeks old; 295 (SD 10.6) g ( $n$ 15)) were administered glucose $(2 \mathrm{~g} / \mathrm{kg}$ body weight) instead of fructose, and the glucose concentration in the portal vein was measured using the Glucose B-Test.

\section{Design of experiments with fructose-fed rats (Expt 5)}

The procedure of this experiment was essentially the same as that for Expt 1 with the following exceptions: rats (5 weeks old; 152 (SD 5.2) $\mathrm{g}(n$ 14)) were divided into two groups (each seven rats), and fed the fructose diet with or without ELE ( $10 \mathrm{~g} / \mathrm{kg}$ of diet) for 5 weeks.

\section{Statistical analyses}

The body weight changes in rats during the feeding of the starch or sucrose diet for 5 weeks were compared between the ELE and control groups by three-way ANOVA for repeated measures, and post hoc analyses were performed by the Newman-Keuls method. Data on the body weight, liver and epidydimal adipose tissue weights, plasma glucose concentration, plasma and hepatic TG concentrations, and food intake in rats fed the starch or sucrose diet with or without ELE for 5 weeks were evaluated by two-way ANOVA, and multiple comparisons were done by the Newman-Keuls method. All other data were analysed by one-way ANOVA, followed by Scheffé post hoc test. These statistical analyses were performed with GB-Stat 5.4 (Dynamic Microsystems, Silver Spring, MD, USA). All results are presented as means and standard deviations, and statistical significance is defined as $P<0.05$.

\section{Results}

Effects of eucalyptus leaf extract on sucrose-fed rats (Expts 1 and 2)

Rats were fed a diet containing starch or sucrose as the major energy source (about $75 \%$ total energy) for 5 weeks, and the effect of ELE, which was supplemented into the diet $(10 \mathrm{~g} / \mathrm{kg}$ diet), on the body weight gain was examined (Expt 1). As shown in Fig. 1, no significant difference in the body weight gain was observed between the ELE and control groups on the starch diet. However, for the rats fed the sucrose diet, the body weight increase was significantly suppressed by the addition of ELE into the diet. The dietary sucrose resulted in an enlarged liver, and the liver weight, even normalized to the body weight, was significantly greater in the sucrose-fed rats, compared with the starch-fed ones (Table 1). In addition, the epidydimal adipose tissue weight, normalized to the body weight, was also increased in the sucrose-fed rats $(P<0 \cdot 05)$. These changes in the liver and epidydimal adipose tissue weights due to the dietary sucrose were suppressed when ELE was added into the diet $(P<0 \cdot 05)$. The plasma and hepatic concentrations of TG were elevated at significantly higher levels in the rats fed the sucrose diet compared with the starch-fed ones, and the elevated concentrations of TG in the plasma and liver were significantly reduced by the addition of ELE to the diet. The plasma glucose concentration was also higher in the sucrose-fed rats than in the starch-fed ones $(P<0.05)$, but a statistically significant decrease in the glucose concentration was not observed by the addition of ELE to the

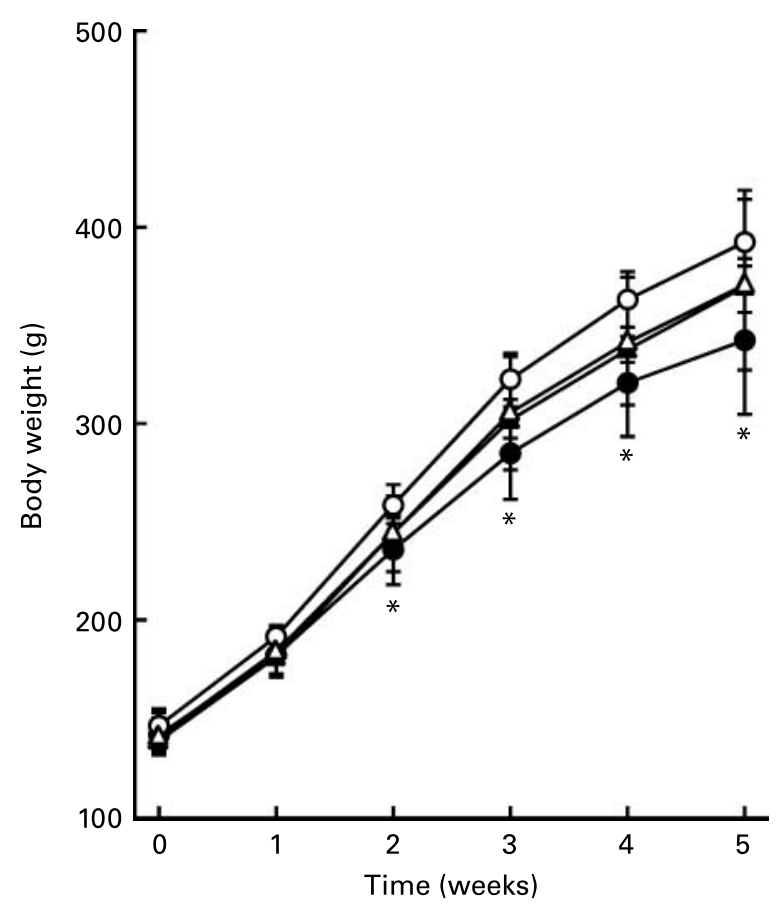

Fig 1. Effect of eucalyptus leaf extract (ELE) on body weight increase in rats fed sucrose (Expt 1). Rats (5 weeks old) were fed the starch $(\triangle, \boldsymbol{\Delta})$ or sucrose $(\bigcirc, \bullet)$ diet with (ELE group $\bullet, \mathbf{\Lambda})$ or without (control group $\mathrm{O}, \triangle)$ ELE $(10 \mathrm{~g} / \mathrm{kg}$ diet) for 5 weeks, and body weight change was followed during the feeding. Values are the means of seven rats with their standard deviations. ${ }^{*} P<0.05 \mathrm{v}$. the control group fed the same diet at the same time point.

sucrose-fed diet. ELE did not induce any significant effects on the food intake in either the starch- or sucrose-fed rats.

For further clarifying the effect of ELE on the dietary sucroseinduced adiposity, rats were fed the sucrose diet containing varied amounts of ELE ( $0-10 \mathrm{~g} / \mathrm{kg}$ diet) for 2 weeks, and the hepatic TG concentration was then determined (Expt 2). As shown in Fig. 2, the hepatic TG concentration decreased by increasing the amount of ELE added to the diet, and a statistically significant decrease in the TG concentration, compared to the rats not receiving ELE, occurred when ELE was supplemented at $1 \mathrm{~g} / \mathrm{kg}$ diet.

When rats were fed the sucrose diet for 2 weeks, the activity of KHK, which catalyses the first step in the fructose metabolism (Mayes, 1993), was enhanced in the liver, compared with the starch-fed rats (24.2 (SD 3.14) v. 13.7 (SD 1.09) nmol/mg protein per min $(n 5) ; P<0.05)$. In addition, the activity of G6PDH, one of the lipogenic enzymes (Iritani, 1992), in the liver was higher in the sucrose-fed rats than in the starch-fed ones (138 (SD 30.2) $v$. 65 (SD 8.4) nmol/mg protein per $\min (n 5) ; P<0.05)$. To examine the effects of ELE on the KHK and G6PDH activities enhanced by the ingestion of sucrose, these enzyme activities were determined in the rats fed the sucrose diet containing varied amounts of ELE $(0-10 \mathrm{~g} / \mathrm{kg}$ diet) for 2 weeks (Expt 2). As shown in Fig. 3, the KHK and G6PDH activities in the sucrose-fed rats were significantly lowered depending on the amount of ELE added to the diet.

\section{Sucrase inhibition by eucalyptus leaf extract (Expt 3)}

The inhibitory effect of ELE on the intestinal sucrase activity was examined in vitro, and was compared with those of the wellknown sucrase inhibitors, $(+)$-catechin and $(-)$-epigallocatechin 
Table 1. Suppressive effect of eucalyptus leaf extract (ELE) on adiposity induced by dietary sucrose in rats (Expt 1$)^{\star}$

(Mean values with their standard deviations, for seven rats in each group)

\begin{tabular}{|c|c|c|c|c|c|c|c|c|}
\hline & \multicolumn{4}{|c|}{ Starch diet } & \multicolumn{4}{|c|}{ Sucrose diet } \\
\hline & \multicolumn{2}{|c|}{ Control group } & \multicolumn{2}{|c|}{ ELE group } & \multicolumn{2}{|c|}{ Control group } & \multicolumn{2}{|c|}{ ELE group } \\
\hline & Mean & SD & Mean & SD & Mean & SD & Mean & SD \\
\hline Body weight $(\mathrm{g})$ & $370^{\mathrm{ab}}$ & $43 \cdot 2$ & $370^{\mathrm{ab}}$ & $13 \cdot 4$ & $392^{\mathrm{a}}$ & $26 \cdot 0$ & $342^{b}$ & $37 \cdot 9$ \\
\hline Liver weight ( $\%$ of body weight) & $3.07^{\mathrm{b}}$ & 0.186 & $3.06^{\mathrm{b}}$ & 0.131 & $4.08^{a}$ & 0.288 & $3 \cdot 38^{\mathrm{b}}$ & 0.301 \\
\hline Adipose tissue weight ( $\%$ of body weight) & $1.58^{\mathrm{b}}$ & 0.155 & $1.56^{\mathrm{b}}$ & 0.224 & $1.87^{\mathrm{a}}$ & 0.141 & $1.50^{\mathrm{b}}$ & 0.159 \\
\hline Plasma glucose $(\mathrm{mmol} / \mathrm{l})$ & $6 \cdot 25^{\mathrm{b}}$ & 0.406 & $6 \cdot 13^{\mathrm{b}}$ & 0.555 & $7 \cdot 39^{a}$ & 0.620 & $6 \cdot 75^{\mathrm{ab}}$ & 0.902 \\
\hline Plasma TG $(\mathrm{mmol} / \mathrm{l})$ & $1 \cdot 78^{\mathrm{b}}$ & 0.361 & $1 \cdot 81^{\mathrm{b}}$ & 0.444 & $2 \cdot 79^{a}$ & 0.677 & $1.44^{b}$ & 0.448 \\
\hline Hepatic TG $(\mu \mathrm{mol} / \mathrm{g})$ & $28 \cdot 2^{\mathrm{b}}$ & $7 \cdot 01$ & $25 \cdot 3^{\mathrm{b}}$ & $7 \cdot 17$ & $44 \cdot 1^{\mathrm{a}}$ & $16 \cdot 28$ & $19 \cdot 1^{\mathrm{b}}$ & 5.07 \\
\hline Food intake (g) & $791^{a}$ & $52 \cdot 5$ & $773^{a}$ & $31 \cdot 7$ & $807^{a}$ & $43 \cdot 2$ & $764^{a}$ & $61 \cdot 1$ \\
\hline
\end{tabular}

\section{TG, triacylglycerol(s)}

a,b Mean values within a row with unlike superscript letters were significantly different $(P<0.05)$.

${ }^{*}$ Rats (5 weeks old; 142 (SD8.6) g ( $n$ 28)) were fed the starch or sucrose diet without (control group) or with (ELE group) ELE (10 g/kg diet) for 5 weeks, and the body weight, liver and epidydimal adipose tissue weights (normalized to the body weight), plasma glucose concentration, plasma and hepatic TG concentrations, and food intake were determined.

3-O-gallate (Matsumoto et al. 1993). As shown in Table 2, sucrase activity was inhibited by ELE in a concentration-dependent manner, and a $50 \%$ inhibition was observed at about $3 \mathrm{mg} /$ $\mathrm{ml}$. However, the inhibitory effect of ELE was weaker when compared with either catechin or epigallocatechin 3-O-gallate.

Inhibitive effect of eucalyptus leaf extract on intestinal fructose absorption (Expt 4)

Rats were orally given ELE 10 min before the administration of fructose, and the effect of ELE on the intestinal fructose absorption, which was determined by measuring the elevated concentration of fructose in the portal vein, was examined. In the rats treated without ELE, the fructose concentration in the portal vein was greatly elevated at $30 \mathrm{~min}$ after the fructose administration (Fig. 4). The elevation of the fructose concentration was significantly inhibited by the treatment with ELE in a dose-dependent manner, and a $45 \%$ inhibition was observed at a dose of

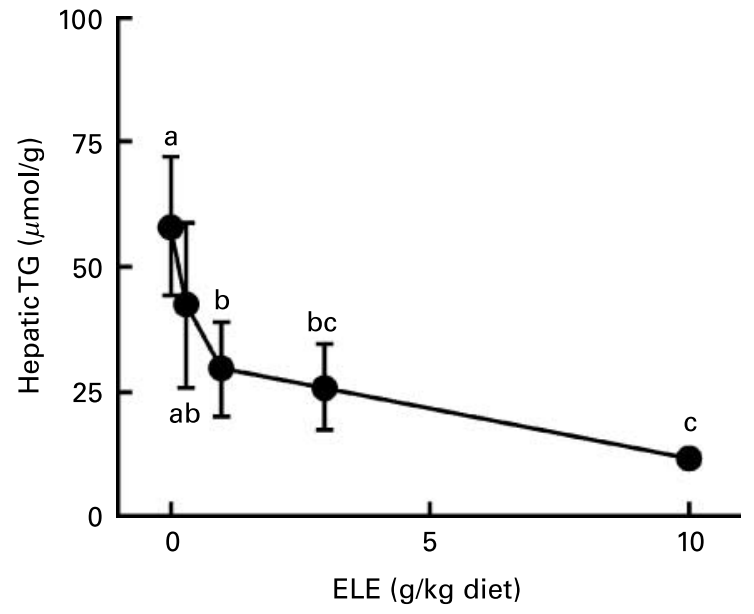

Fig. 2. Hepatic triacylglycerol (TG) concentration in rats fed the sucrose diet containing varied amounts of eucalyptus leaf extract (ELE) (Expt 2). Rats ( 5 weeks old) were fed the sucrose diet containing varied amounts of ELE $(0-10 \mathrm{~g} / \mathrm{kg}$ of diet) for 2 weeks, and the hepatic concentration of TG was determined. Values are the means of five rats with their standard deviations shown by vertical bars. Values with unlike letters were significantly different $(P<0.05)$.
$0 \cdot 1 \mathrm{~g} / \mathrm{kg}$ body weight. In contrast, when glucose was substituted for fructose, the elevation of the glucose concentration in the portal vein was barely affected by the treatment with ELE even at the high dose of $1 \mathrm{~g} / \mathrm{kg}$ body weight.
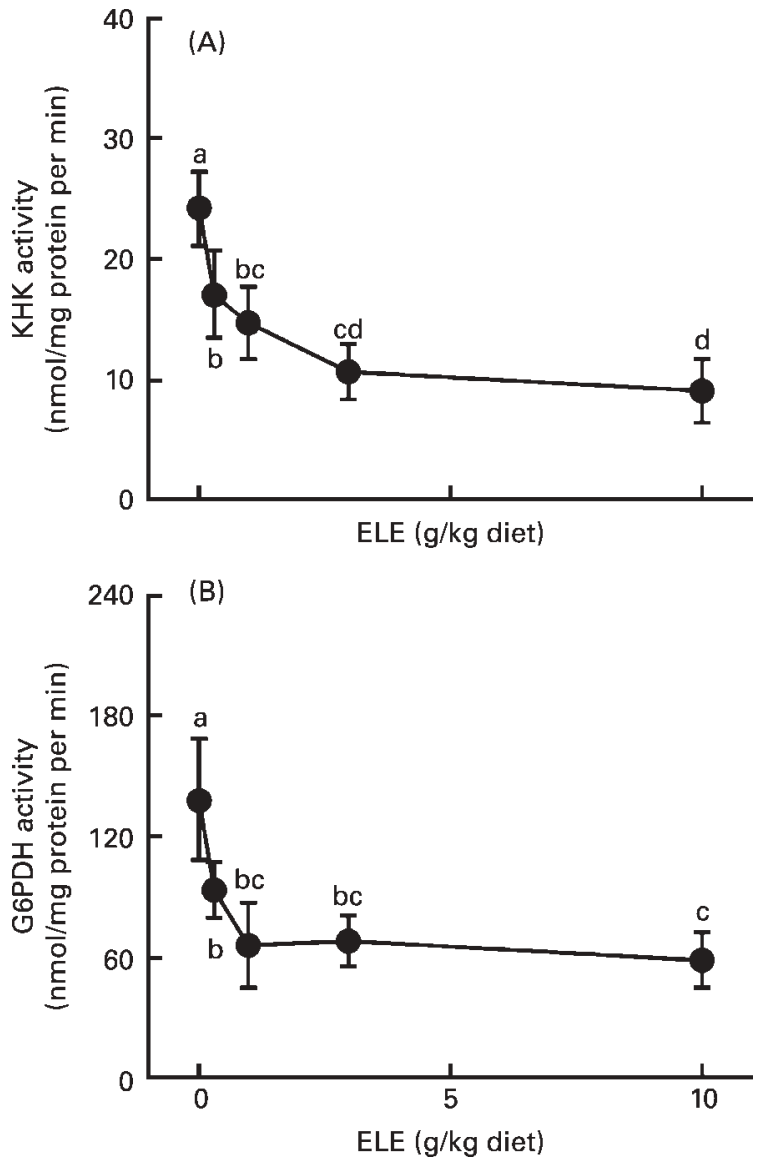

Fig. 3. Hepatic ketohexokinase (KHK) and glucose 6-phosphate dehydrogenase (G6PDH) activities in rats fed the sucrose diet containing varied amounts of eucalyptus leaf extract (ELE) (Expt 2). Rats (5 weeks old) were fed the sucrose diet containing varied amounts of ELE $(0-10 \mathrm{~g} / \mathrm{kg}$ diet) for 2 weeks, and the hepatic $\mathrm{KHK}(\mathrm{A})$ and G6PDH (B) activities were determined. Values are the means of five rats with their standard deviations shown by vertical bars. Values with unlike letters were significantly different $(P<0.05)$. 
Table 2. Inhibition of intestinal sucrase activity by eucalyptus leaf extract (ELE) in vitro (Expt 3)*

(Mean values with their standard deviations of four determinations)

\begin{tabular}{|c|c|c|}
\hline & \multicolumn{2}{|c|}{ Relative activity (\%) } \\
\hline & Mean & SD \\
\hline Control & 100 & $5 \cdot 87$ \\
\hline \multicolumn{3}{|l|}{ ELE } \\
\hline $1 \mathrm{mg} / \mathrm{ml}$ & $77 \cdot 2$ & $2 \cdot 18$ \\
\hline $3 \mathrm{mg} / \mathrm{ml}$ & $50 \cdot 3$ & $2 \cdot 14$ \\
\hline $10 \mathrm{mg} / \mathrm{ml}$ & $21 \cdot 0$ & 4.26 \\
\hline \multicolumn{3}{|l|}{ Catechin } \\
\hline $1 \mathrm{mg} / \mathrm{ml}$ & $57 \cdot 1$ & $6 \cdot 79$ \\
\hline $3 \mathrm{mg} / \mathrm{ml}$ & $33 \cdot 2$ & $5 \cdot 74$ \\
\hline $10 \mathrm{mg} / \mathrm{ml}$ & $10 \cdot 1$ & 0.26 \\
\hline \multicolumn{3}{|c|}{ Epigallocatechin 3-O-gallate } \\
\hline $0.05 \mathrm{mg} / \mathrm{ml}$ & $67 \cdot 4$ & 3.41 \\
\hline $0.1 \mathrm{mg} / \mathrm{ml}$ & $52 \cdot 2$ & 1.76 \\
\hline $0.2 \mathrm{mg} / \mathrm{ml}$ & $32 \cdot 8$ & 3.88 \\
\hline
\end{tabular}

* Sucrase activity was determined in vitro in the presence of ELE, $(+)$-catechin or $(-)$-epigallocatechin 3-O-gallate at the concentration cited. Data are presented as percentage of control (without any inhibitors).

\section{Effects of eucalyptus leaf extract on fructose-fed rats (Expt 5)}

To explore whether ELE can effectively suppress adiposity induced by dietary fructose, rats were fed a high-fructose diet that contained ELE at $10 \mathrm{~g} / \mathrm{kg}$ diet for 5 weeks. As shown in Table 3, the body weight of the fructose-fed rats was not significantly changed by the addition of ELE to the diet. In addition, the liver weight, plasma glucose concentration and food intake were barely different between the ELE and control groups. However, the epidydimal adipose tissue weight (normalized to the body weight) was significantly lower in the ELE group than in the control. Furthermore, the supplementation of ELE resulted in a significant reduction of the plasma and hepatic concentrations of TG

\section{Discussion}

Fructose absorbed in the small intestine is delivered mainly to the liver. The first step of the fructose metabolism in the liver is its phosphorylation by the action of KHK (fructokinase) to produce fructose 1-phosphate (Mayes, 1993). The produced fructose 1phosphate is split by aldolase B into glyceraldehyde and dihydroxyacetone phosphate, a member of the intermediates in the glycolytic sequence. The third enzyme of the fructose metabolism is triokinase, which catalyses the phosphorylation of glyceraldehyde by ATP to form glyceraldehyde 3-phosphate, another intermediate of the glycolytic pathway. Thus, one fructose molecule is metabolized into two triose phosphates that bypass the main ratecontrolling step in glycolysis, 6-phosphofructokinase.

Fructose can provide carbon atoms for both the glycerol and acyl portions of the TG molecules. High concentrations of fructose can serve as a relatively unregulated source of acetyl-CoA, in contrast to glucose whose uptake and metabolism are regulated as the level of 6-phosphofructokinase, which is inhibited by citrate and ATP (Mayes, 1993). Therefore, fructose is more lipogenic than glucose, and the plasma and hepatic concentrations of TG are significantly elevated when large amounts of fructose or sucrose are fed to rats (Fukuda et al. 1983).

In this study, the plasma and hepatic concentrations of TG elevated in the rats fed the sucrose diet were significantly decreased when ELE was added to the diet (Table 1; Fig. 2). In contrast, ELE did not show any significant effects on the plasma and hepatic TG concentrations in the starch-fed rats. In addition, the body weight gain and epidydimal adipose tissue weight were also significantly reduced by ELE in the sucrose-fed rats (but not in the starch-fed ones) (Fig. 1 and Table 1). These results indicate that dietary sucrose-induced lipogenesis and obesity are suppressed when ELE is ingested. Food intake was not affected by ELE in the sucrose-fed rats as well as the starch-fed ones (Table 1), indicating that ELE does not have toxic effects on the rats that might inhibit food intake, and therefore, body weight gain.

It has been reported that KHK activity is enhanced in the liver to stimulate fructose metabolism when rats are fed sucrose or fructose (Fukuda \& Iritani, 1984; Hallfrish, 1990; Werman \& Bhathena, 1995). In addition, the feeding of sucrose or fructose results in increases in the lipogenic enzymes, such as fatty acid synthase, acetyl-CoA carboxylase and G6PDH, in the liver (Fukuda et al. 1983; Iritani, 1992; Osaki et al. 2001). The KHK
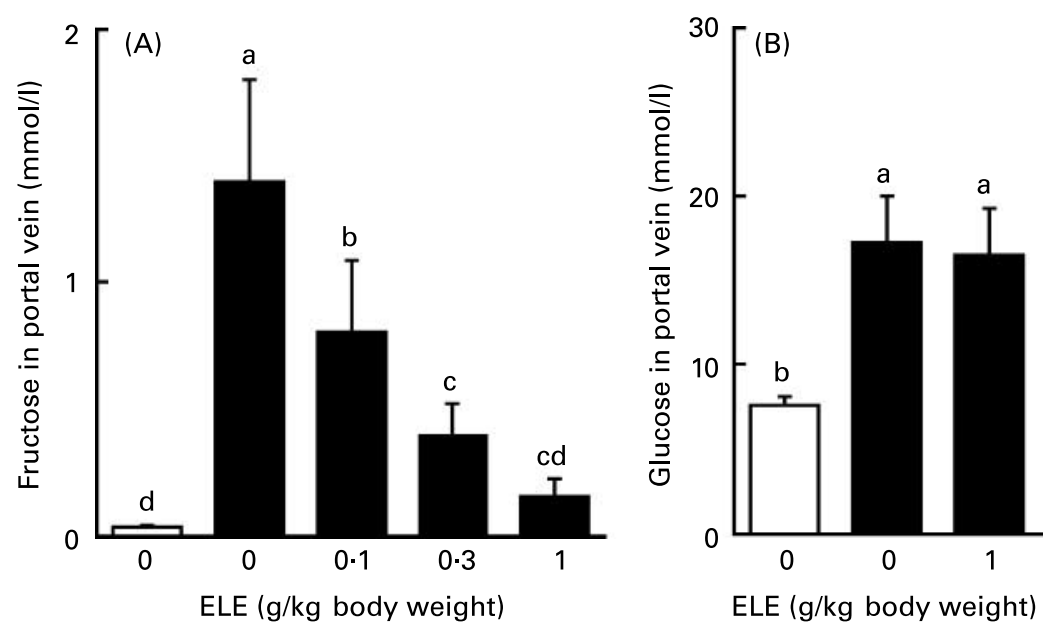

Fig. 4. Effects of eucalyptus leaf extract (ELE) on intestinal fructose and glucose absorption (Expt 4). Rats (8 weeks old), which had been starved for $16 \mathrm{~h}$, were orally given ELE at a dose cited. Ten minutes later, these rats were orally administered the solution without ( $\square$ ) or with ( $\square)$ fructose (A) or glucose (B) (2 g/kg body weight; dissolved in $0.5 \mathrm{ml}$ water), and the fructose or glucose concentration in the portal vein was determined 30 min after the administration of sugar. Values are the means of five rats with their standard deviations shown by vertical bars. Values with unlike letters were significantly different $(P<0.05)$. 
Table 3. Suppressive effect of eucalyptus leaf extract (ELE) on adiposity in rats fed the fructose diet (Expt 5) $\dagger$

(Mean values with their standard deviations for seven rats in each group)

\begin{tabular}{|c|c|c|c|c|}
\hline & \multicolumn{2}{|c|}{ Control group } & \multicolumn{2}{|c|}{ ELE group } \\
\hline & Mean & SD & Mean & SD \\
\hline Body weight (g) & 394 & $25 \cdot 9$ & 387 & $14 \cdot 2$ \\
\hline Liver weight ( $\%$ of body weight) & 3.47 & 0.274 & 3.47 & 0.416 \\
\hline $\begin{array}{l}\text { Adipose tissue weight (\% of body } \\
\text { weight) }\end{array}$ & $1 \cdot 76$ & 0.298 & $1 \cdot 43^{*}$ & 0.279 \\
\hline Plasma glucose (mmol/l) & $6 \cdot 87$ & 0.680 & $6 \cdot 31$ & 0.689 \\
\hline Plasma TG (mmol/l) & 2.50 & 0.488 & $1 \cdot 69^{*}$ & 0.299 \\
\hline Hepatic TG $(\mu \mathrm{mol} / \mathrm{g})$ & $41 \cdot 8$ & $8 \cdot 13$ & $15 \cdot 6^{\star}$ & $5 \cdot 25$ \\
\hline Food intake (g) & 817 & $31 \cdot 3$ & 817 & $37 \cdot 7$ \\
\hline
\end{tabular}

TG, triacylglycerol(s)

${ }^{*} P<0.05$ v. control group.

†Rats (5 weeks old; $152(\operatorname{sD} 5.2) \mathrm{g}(n$ 14)) were fed the fructose diet without (control group) or with (ELE group) ELE ( $10 \mathrm{~g} / \mathrm{kg}$ diet) for 5 weeks, and the body weight, liver and epidydimal adipose tissue weights (normalized to the body weight), plasma glucose concentration, plasma and hepatic TG concentrations, and food intake were determined.

and G6PDH activities enhanced in the sucrose-fed rats were significantly lowered by the addition of ELE to the diet (Fig. 3). These results indicate that the activation of the fructose metabolism and fatty acid synthesis induced by dietary sucrose is prevented when ELE is ingested.

L-Arabinose has been reported to suppress dietary sucrosestimulated lipogenesis by inhibiting the sucrase reaction in the small intestine (Osaki et al. 2001). ELE showed an inhibitory activity for the intestinal sucrase reaction in vitro, although the inhibitory effect was weaker than catechin and epigallocatechin 3-O-gallate (Table 2). The plant genus Eucalyptus produces many kinds of hydrolysable tannins (Cadahía et al. 1997; Hou et al. 2000; Santos \& Waterman, 2001), and certain hydrolysable tannins, such as $1,2,3,4,6$-penta- $O$-galloyl- $\beta$-glucose, have been reported to have the ability to inhibit the sucrase activity (Toda et al. 2001). Therefore, the sucrase inhibition by hydrolysable tannins seems to be one of the mechanisms by which ELE suppresses adiposity due to dietary sucrose. 1,2,3,4,6-Penta- $O$-galloyl- $\beta$-glucose was found in ELE as one of the major hydrolysable tannins having a sucrase inhibitory activity (data not shown).

Glucose is taken up from the lumen of the small intestine by the $\mathrm{Na}^{+} /$glucose co-transporter, SGLT1, which utilizes the electrochemical $\mathrm{Na}^{+}$gradient to transport the sugar against its concentration gradient (Wright, 1993). In contrast, fructose is transported across the intestinal brush-border membranes by GLUT5, a member of the facilitative glucose transporter family that possesses a very strict stereospecificity for fructose (Gould \& Holman, 1993; Mahraoui et al. 1994). When rats were orally given ELE 10 min before the administration of fructose, the fructose absorption in the small intestine was inhibited in a dose-dependent manner (Fig. 4). In contrast, the intestinal glucose absorption was barely affected by the treatment with ELE. These results indicate that inhibitor(s) specific for GLUT5 without showing any effects on SGLT1 are contained in ELE. It is also suggested that ELE exerts a suppression on the adiposity due to the extreme ingestion of sucrose by inhibiting the intestinal fructose absorption in addition to the sucrase inhibition. However, the active component(s) of ELE that inhibit the intestinal fructose absorption remain to be elucidated.

Sucrase inhibitors, such as L-arabinose, cannot suppress adiposity when large amounts of fructose, instead of sucrose, are ingested (Osaki et al. 2001). In contrast, ELE was able to reduce the epidydimal adipose tissue weight and the plasma and hepatic TG concentrations in the fructose-fed rats as well as in the sucrose-fed ones (Table 3). These results strongly support the fact that the intestinal fructose absorption is inhibited by ELE.

In summary, data obtained in the present study show that ELE possesses a unique biological activity to inhibit the intestinal fructose absorption in addition to the sucrase inhibition, and that adiposity induced by the extreme ingestion of sucrose or fructose is prevented by ELE in rats. As far as we know, this is the first report showing that an inhibitory activity specific for the absorption of fructose in the small intestine is found in foods or food additives.

\section{Acknowledgements}

We thank Dr Kameoka, Kinki University, for his extensive discussions. This work was supported by Grant-in-Aid (14560107) for Scientific Research (to H. I.) from the Japan Society for the Promotion of Science.

\section{References}

Amakura Y, Umino Y, Tsuji S, Ito H, Hatano T, Yoshida T \& Tonogai Y (2002) Constituents and their antioxidative effects in eucalyptus leaf extract used as a natural food additive. Food Chem 77, 47-56.

Ameyama M, Shinagawa E, Matsushita K \& Adachi O (1981) D-Fructose dehydrogenase of Gluconobacter industrius: purification, characterization, and application to enzymatic microdetermination of D-fructose. $J$ Bacterio 145, 814-823.

Bais R, James HM, Rofe AM \& Conyers RA (1985) The purification and properties of human liver ketohexokinase. A role for ketohexokinase and fructose-bisphosphate aldolase in the metabolic production of oxalate from xylitol. Biochem J 230, 53-60.

Bradford MM (1976) A rapid and sensitive method for the quantitation of microgram quantities of protein utilizing the principal of protein dyebinding. Anal Biochem 72, 248-254.

Cadahía E, Conde E, García-Vellejo MC \& Fernández de Simón B (1997) Tannin composition of Eucalyptus camaldulensis. E. globulus and E. rudis. Part I. Wood. Holzforshung 51, 119-124.

Elliott SS, Keim NL, Stern JS, Teff K \& Havel PJ (2002) Fructose, weight gain, and the insulin resistance syndrome. Am J Clin Nutr 76, 911-922.

Fukuda H \& Iritani N (1984) Effects of aging on changes in substrate and effector levels of rat-liver glycolytic and lipogenic enzymes during induction. Biochim Biophys Acta 795, 79-84.

Fukuda H, Iritani N \& Tanaka T (1983) Effects of high-fructose diet on lipogenic enzymes and their substrate and effector levels in diabetic rats. J Nutr Sci Vitaminol 29, 691-699.

Glock GE \& MaLean P (1953) Further studies on the properties and assay of glucose-6-phosphate dehydrogenase and 6-phosphogluconate dehydrogenase of rat liver. Biochem J 55, 400-409.

Gould GW \& Holman GD (1993) The glucose transporter family: structure, function and tissue-specific expression. Biochem J 295, 329-341.

Gray AM \& Flatt PR (1998) Antihyperglycemic actions of Eucalyptus globulus (eucalyptus) are associated with pancreatic and extra-pancreatic effects in mice. $J$ Nutr 128, 2318-2323.

Hallfrish J (1990) Metabolic effects of dietary fructose. FASEB J 4, 2652-2660.

Hou A-J, Liu Y-Z, Yang H, Lin Z-W \& Sun H-D (2000) Hydrolyzable tannins and related polyphenols from Eucalyptus globulus. J Asian Nat Prod Res 2, 205-212.

Iritani N (1992) Nutritional and hormonal regulation of lipogenic-enzyme gene expression in rat liver. Eur J Biochem 205, 433-442. 
Japanese Ministry of Health and Welfare (1999) Food Sanitation Law, Annex1-44. Tokyo: Japan Food Additive Association.

Mahraoui E, Takeda J, Mesonero J, Chantret I, Dussaulx E, Bell GI \& Brot-Laroche E (1994) Regulation of expression of the human fructose transporter (GLUT5) by cyclic AMP. Biochem J 301, $169-175$.

Matsumoto N, Ishigaki F, Ishigaki A, Iwashina H \& Hara Y (1993) Reduction of blood-glucose levels by tea catechin. Biosci Biotechnol Biochem 57, 525-527.

Mayes PA (1993) Intermediary metabolism of fructose. Am J Clin Nutr 58, 754S-765S

Osaki S, Kimura T, Sugimoto T, Hizukuri S \& Iritani N (2001) L-Arabinose feeding prevents increase due to dietary sucrose in lipogenic enzymes and triacylglycerol levels in rats. J Nutr 131, 796-799.

Santos SC \& Waterman PG (2001) Polyphenols from Eucalyptus consideniana and Eucalyptus viminalis. Fitoterapia 72, 95-97.
Takasaki M, Konoshima T, Fujitani K, Yoshida S, Nishimura H, Tokuda H, Nishino H, Iwashima A \& Kozuka M (1990) Inhibitors of skintumor promotion. VIII. Inhibitory effects of euglobals and their related compounds on Epstein-Barr virus activation (1). Chem Pharm Bull 38, 2723-2739.

Takenoshita M, Yamaji R, Inui H \& Nakano Y (1998) Suppressive effect of insulin on the synthesis of sucrase-isomaltase complex in small intestinal epithelial cells, and abnormal increase in the complex under diabetic conditions. Biochem J 329, 597-600.

Toda M, Kawabata J \& Kasai T (2001) Inhibitory effects of ellagi- and gallotannins on rat intestinal $\alpha$-glucosidase complexes. Biosci Biotechnol Biochem 65, 542-547.

Werman MJ \& Bhathena SJ (1995) Fructose metabolizing enzymes in the rat liver and metabolic parameters: interaction between dietary copper, type of carbohydrates, and gender. Nutr Biochem 6, 373-379.

Wright EM (1993) The intestinal $\mathrm{Na}^{+} /$glucose cotransporter. Annu Rev Physiol 55, 575-589. 